\title{
O USO DE MATERIAL GENÉTICO NA ELUCIDAÇÃO DE CRIMES CONTRA A VIDA HUMANA: UMA REVISÃO SISTEMÁTICA
}

\author{
THE USE OF GENETIC MATERIAL IN THE ELUCIDATION OF CRIMES AGAINST \\ LIFE: A SYSTEMATIC REVIEW
}

Vanessa Rizzon Rodrigues ${ }^{1}$

Edegar Fronza ${ }^{2}$

RESUMO Objetivo: analisar a produção científica relativa ao uso de material genético na elucidação de crimes contra a vida humana. Método: revisão sistemática da literatura, realizada durante o período de janeiro e fevereiro de 2021 nas bases de dados: LILACS SciELO, PubMed e ScienceDirect. Para as buscas foram incluídos estudos nacionais e internacionais, originais, publicados no idioma português e/ou inglês, disponíveis eletronicamente na íntegra, entre os anos de 2000 a 2020. Resultados: foram selecionados II estudos para análise final, que versaram sobre o uso de material genético em casos de violência sexual, presença de DNA em amostras de unhas em homicídios, uso de DNA na liberação de vítimas com condenações injustas, abertura de casos de crimes não resolvidos, uso da genética forense comportamental em processos criminais, padrão tri-alélico de curtas repetições em casos de assassinato envolvendo gêmeos monozigóticos, marcadores de metilação de DNA dependentes da idade e avaliação de casos a partir de novas hipóteses investigativas. Discussão: a biologia molecular tem papel importante na investigação, elucidação de crimes de natureza grave, além de contribuir na redução de impunidade e resolução de condenações injustas. A utilização de material genético e/ou a análise de perfis de DNA tem sido uma ferramenta utilizada de forma ampla pela perícia técnica e esta tem possibilitado identificar com precisão os autores dos crimes. Considerações finais: novas investigações científicas no contexto da biologia molecular podem fortalecer e qualificar o processo de elucidação de casos hediondos pela justiça criminal.

Palavras-chave: Biologia. Crime. Genética Forense.

ABSTRACT Objective: to analyze the scientific production related to the use of genetic material in the elucidation of crimes against human life. Method: systematic review of the literature carried out during the period of January and February 2021 in the databases: LILACS SCiELO, PubMed and ScienceDirect. Original national and international studies, published in Portuguese and / or English, available electronically in full, between the years 2000 to 2020 were included in the research. Results: II studies were selected for final analysis, those which dealt with the use of genetic material in cases of sexual

\footnotetext{
${ }^{\text {I }}$ Acadêmica do curso de Bacharelado em Ciências Biológicas da Universidade de Caxias do Sul, RS, Brasil. E-mail: vrrodrigues@ucs.br.

${ }^{2}$ Doutor em Biotecnologia pela Universidade de Caxias do Sul. Docente da Área de Conhecimento de Ciências da Vida da Universidade de Caxias do Sul- RS, Brasil. Mestre em Biociências pela Pontifícia Universidade Católica do Rio Grande Do Sul - PUCRS,. E-mail: efronza@ucs.br.
} 
violence, presence of DNA in nail samples in homicides, use of DNA in releasing victims who have been unfairly convicted, opening cases of unsolved crimes, use of behavioral forensic genetics in criminal proceedings, tri-allelic pattern of short repetitions in murder cases involving monozygotic twins, age-dependent DNA methylation markers and case evaluation from new investigative hypotheses. Discussion: molecular biology plays an important role in the investigation, elucidation of serious crimes, in addition to contributing to the reduction of impunity and the resolution of unfair convictions. The use of genetic material and / or the analysis of DNA profiles has been a tool widely used by technical experts and that has made it possible to accurately identify the perpetrators of crimes. Final considerations: new scientific investigations in the context of molecular biology can empower and qualify the process of elucidating heinous cases by criminal justice.

Keywords: Biology. Crime. Forensic Genetics.

\section{INTRODUÇÃO}

A ciência forense constitui uma área do conhecimento ampla que visa colaborar na investigação judicial e criminal, podendo se subdividir em subáreas como a toxicologia forense, química forense, genética forense, entomologia forense. Neste contexto, a biologia tem se tornado elemento indispensável no processo de investigação de crimes contra a vida (SANTOS 2018).

A nível global, o aprimoramento científico e de técnicas genéticas tem consolidado a genética forense como parte do sistema criminal, na busca pela justiça, redução da impunidade e diminuição de imprecisões processuais. Um dos aspectos possíveis no uso da genética forense no campo da investigação criminal é a possibilidade de extrair perfis de DNA (ácido Desoxirribonucleico) (DIAS FILHO et al., 2020).

O DNA forense encontra-se tanto no núcleo como nas mitocôndrias das células, logo amostras de tecido ou fluido biológico podem ser utilizadas como fonte de DNA para investigação e elucidação de crimes (BEZERRA, 2004). Desta forma, a análise de DNA é realizada a partir de qualquer tipo de amostra que contenha material genético, como presença de pequena amostra de sangue, saliva, pele ou sêmen, cabelo, urina, unha, ossos, líquido amniótico, vilosidade coriônica, fígado, músculo, suor e fezes, sendo possível identificar uma vítima ou um suspeito (FERREIRA, 2016; MILLARD, 2015; SANTOS, 2018). Assim sendo, o DNA forense é aplicado na identificação de suspeito em casos de crimes sexuais, identificação de cadáveres carbonizados, em decomposição, mutilados, 
relação entre instrumento lesivo e vítima, identificação de cadáveres abandonados, aborto provocado, infanticídio, investigação de paternidade que envolve gestação em situação de violência sexual, estudo de vínculo genético, entre outros (LEITE et al., 2005; DOLINSKY, PEREIRA, 2007).

Neste contexto, a biologia molecular compreende a área do conhecimento que estuda o material genético e a sua estrutura, englobando seus produtos de expressão, proteínas e as características genéticas geracionais. Com o avanço tecnológico e modernas técnicas de análise molecular, esta se ocupa da análise do DNA em identificar um indivíduo a partir de fluidos corporais e de outras amostras encontradas no local do crime (BROWN, 200I). Portanto, a biologia molecular nas ciências forenses inclui desde a coleta de amostras biológicas, extração, purificação e quantificação do DNA, análise dos loci, visualização dos fragmentos e caracterização através de Eletroforese e Proteína C-reativa (PCR), interpretação e análise dos resultados (SCHLLER, SCHEITHAUER, 2009).

Outra contribuição da genética forense no sistema de justiça criminal é a criação e ampliação de bancos de dados nacionais e internacionais centralizados, que contêm perfis genéticos inseridos e armazenados em função dos critérios definidos na legislação de cada país. Estes bancos têm como objetivo colaborar para a resolução de ações criminais e judiciais, contribuindo como instrumento de investigação. Estes possibilitam a comparação automática de perfis genéticos provenientes de diversas circunstâncias, como amostras de DNA não identificados em cenas de crimes e amostras de referência de condenados, vítimas e suspeitos (BONACCORSO, 2010).

Apesar de o Brasil contar com a lei 12.654/12, que regulamenta a criação e uso de bancos de dados de perfis genéticos para fins de investigação criminal, a legislação encontra-se limitada com relação à de outros países, uma vez que esta preconiza a coleta de material biológico e a inserção de perfil genético de indivíduos julgados por crimes dolosos, violência grave e de caráter hediondo (BRASIL, 2012a). Segundo o Ministério da Justiça e Segurança Pública (MJSP), o Banco Nacional de Perfis Genéticos (BNPG) conta com 6.50o perfis genéticos de condenados, 440 de investigados e 7.800 perfis de vestígios de local de crime. No Brasil, até o ano de 2019, 559 investigações foram auxiliadas por essa ferramenta. O objetivo é ampliar o banco, coletando material de todos os condenados em 
crimes dolosos no país, visando alcançar mais de 750 mil perfis até 2022, além de ampliar o cadastro de registros biológicos no BNPG, conferindo maior eficiência no processo de investigação e prova (BRASÍLIA, 2019).

Este estudo se justifica pela relevância da temática uma vez que se ocupa com a investigação e elucidação de crimes contra a vida humana e contribui com a justiça criminal e a sociedade, aumentando a pena e reduzindo a impunidade. Acredita-se que o estudo possa contribuir na construção do conhecimento, evidenciando a importância da genética na prática forense, além de suscitar a necessidade de novas investigações nesta área. A partir disso, tem-se a seguinte questão de pesquisa: Como a produção científica aborda o uso de material genético para a elucidação de crimes contra a vida humana?

Para tal, este estudo teve como objetivo analisar a produção científica relativa ao uso de material genético na elucidação de crimes contra a vida humana.

\section{MÉTODO}

Trata-se de uma revisão sistemática de acordo com as diretrizes dos principais itens para relatar Revisões Sistemáticas e Meta-análises (PRISMA) que tem por objetivo qualificar o relato de dados e orientar a avaliação crítica da revisão sistemática e metaanálise já publicada (MOHER et al., 2009; BRASIL, 2012b).

A revisão sistemática da literatura foi realizada a partir das bases de dados on-line LILACS (Literatura Latino-Americana e do Caribe em Ciências da Saúde), SciELO (Scientific Electronic Library Online), PubMed (U.S. National Library of Medicine, U.S. National Institutes of Health) e ScienceDirect.

Para as buscas nestas bases de dados foram utilizados os seguintes descritores (DeCS): "Genética Forense", "Biologia”, “Crime”, "Prova Pericial”, "DNA Mitocondrial”, "Triptofano Hidroxilase”, assim como suas equivalências em inglês (MeSH): "Forensic Genetics", "Biology", "Crime", "Expert Testimony", "DNA, Mitochondrial”, “Tryptophan Hydroxylase”, com o auxílio do operador boleano AND.

Para nortear o presente estudo, formulou-se a seguinte questão de pesquisa: Como a produção científica aborda o uso de material genético para a elucidação de crimes contra a vida humana? 
Para seleção dos estudos desta revisão sistemática foram incluídas publicações originais nacionais e internacionais, no idioma português e/ou inglês, disponíveis eletronicamente na íntegra que retratassem a temática do uso de material genético na elucidação de crimes conta a vida humana.

Foram considerados os últimos 20 anos (2000-2020) de publicação, pois se acredita que neste recorte temporal é possível contemplar as principais produções científicas publicadas e estabelecer uma linha cronológica representativa dos avanços nesta área.

Foram excluídos estudos de revisão, teses, dissertações, monografias, livros, capítulos de livros, documentos governamentais, as duplicidades, produções publicadas em outros idiomas, além daqueles mencionados nos critérios de inclusão e as publicações que não atenderam os critérios estabelecidos. Também foram excluídos estudos que abordassem o desenvolvimento de ferramentas, software, técnicas e protocolos de análise, assim como notas científicas. A pesquisa nas bases de dados foi realizada durante o período de janeiro e fevereiro de 2020.

A estratégia de busca foi realizada da seguinte forma: "Genética Forense" and "Biologia" and "Crime", "Genética Forense" and "Prova Pericial" and "Crime", Genética Forense" and "DNA Mitocondrial" and "Crime", "Genética Forense" and "Triptofano Hidroxilase" and "Crime" e com os descritores na língua inglesa respectivamente. Foi igualmente aplicado o uso de filtros, idioma, ano e tipo de estudo e na base de dados ScienceDirect foi empregado adicionalmente o filtro de áreas temáticas: bioquímica, genética e biologia molecular.

Inicialmente, foram avaliados os títulos e resumos de todos os artigos identificados pela estratégia de busca. Os resumos que forneceram informações suficientes foram selecionados para a avaliação dos textos completos. $\mathrm{Na}$ segunda fase, foram avaliados os artigos na íntegra sendo realizadas as seleções de acordo com os critérios de elegibilidade pré-estabelecidos. Os artigos selecionados foram lidos, revisados e analisados criteriosamente, na busca de informações que correspondiam aos objetivos propostos nesta pesquisa. Nesta etapa, os dados coletados foram analisados através da construção de um quadro sinóptico que abrangeu as seguintes variáveis: título do estudo, autores, ano de publicação, periódico, objetivo do estudo, metodologia, resultados e considerações finais. 
As informações utilizadas nesta pesquisa foram devidamente referenciadas, sendo respeitados e identificados os autores e fontes de pesquisa com devido rigor científica conforme estabelecido na Lei $\mathrm{n}^{\mathrm{O}} \mathrm{12.853/13}$, que regulamenta os direitos autorais no Brasil. (BRASIL, I988; BRASIL, 2013).

\section{RESULTADOS}

Após a busca nas bases de dados com os descritores e filtros previamente definidos foram localizados 515 estudos. A partir da leitura do título e do resumo foram selecionadas I3I publicações, sendo excluídos 117 artigos por não abordar a temática em estudo. Posteriormente a leitura na íntegra das investigações, I4 atendiam aos critérios de elegibilidade, sendo excluídos 3 por apresentarem-se duplicados. Foram selecionados para análise final da revisão sistemática II estudos.

A Tabela I apresenta o número de artigos encontrados na pré-seleção dos estudos, seguido da Figura I com o modelo de fluxograma da pesquisa.

Tabela I. Resultados das buscas por estudos primários nas bases de dados-estratégias de busca.

\begin{tabular}{|l|c|c|c|c|}
\hline $\begin{array}{l}\text { Descritores } \\
\text { (Decs/MeSH) }\end{array}$ & SciELO & PubMed & $\begin{array}{c}\text { Science } \\
\text { Direct }\end{array}$ & Lilacs \\
\hline $\begin{array}{l}\text { Genética Forense" and "DNA } \\
\text { Mitocondrial” and "Crime". }\end{array}$ & 0 & 0 & 0 & 0 \\
\hline $\begin{array}{l}\text { "Forensic Genetic" and "DNA } \\
\text { Mitochondrial” and "Crime". }\end{array}$ & 0 & 17 & 147 & 0 \\
\hline $\begin{array}{l}\text { "Genética Forense" and "Triptofano } \\
\text { Hidroxilase" and "Crime" }\end{array}$ & 0 & 0 & 0 & 0 \\
\hline $\begin{array}{l}\text { Forensic genetic and Tryptophan } \\
\text { Hydroxylase and crime "Prova }\end{array}$ & 0 & 0 & 2 & 0 \\
\hline $\begin{array}{l}\text { "Genética Forense" and "Expert } \\
\text { Pericial" and "Crime" }\end{array}$ & 0 & 3 & 75 & 0 \\
\hline "Genetic Forensic" and & & & 0 & 0 \\
\hline
\end{tabular}




\begin{tabular}{|l|c|c|c|c|}
\hline $\begin{array}{l}\text { Testimony" and "crime". } \\
\text { "Genética Forense" and "Biologia" and } \\
\text { "Crime" }\end{array}$ & 0 & 0 & 0 & 0 \\
\hline $\begin{array}{l}\text { "Forensic Genetics" and "Biology" and } \\
\text { "Crime" }\end{array}$ & 0 & 44 & 227 & 0 \\
\hline Total de estudos por base de dados & 0 & 64 & 451 & 0 \\
\hline
\end{tabular}

Fonte: elaborado pela autora

Figura I: Fluxograma da pesquisa

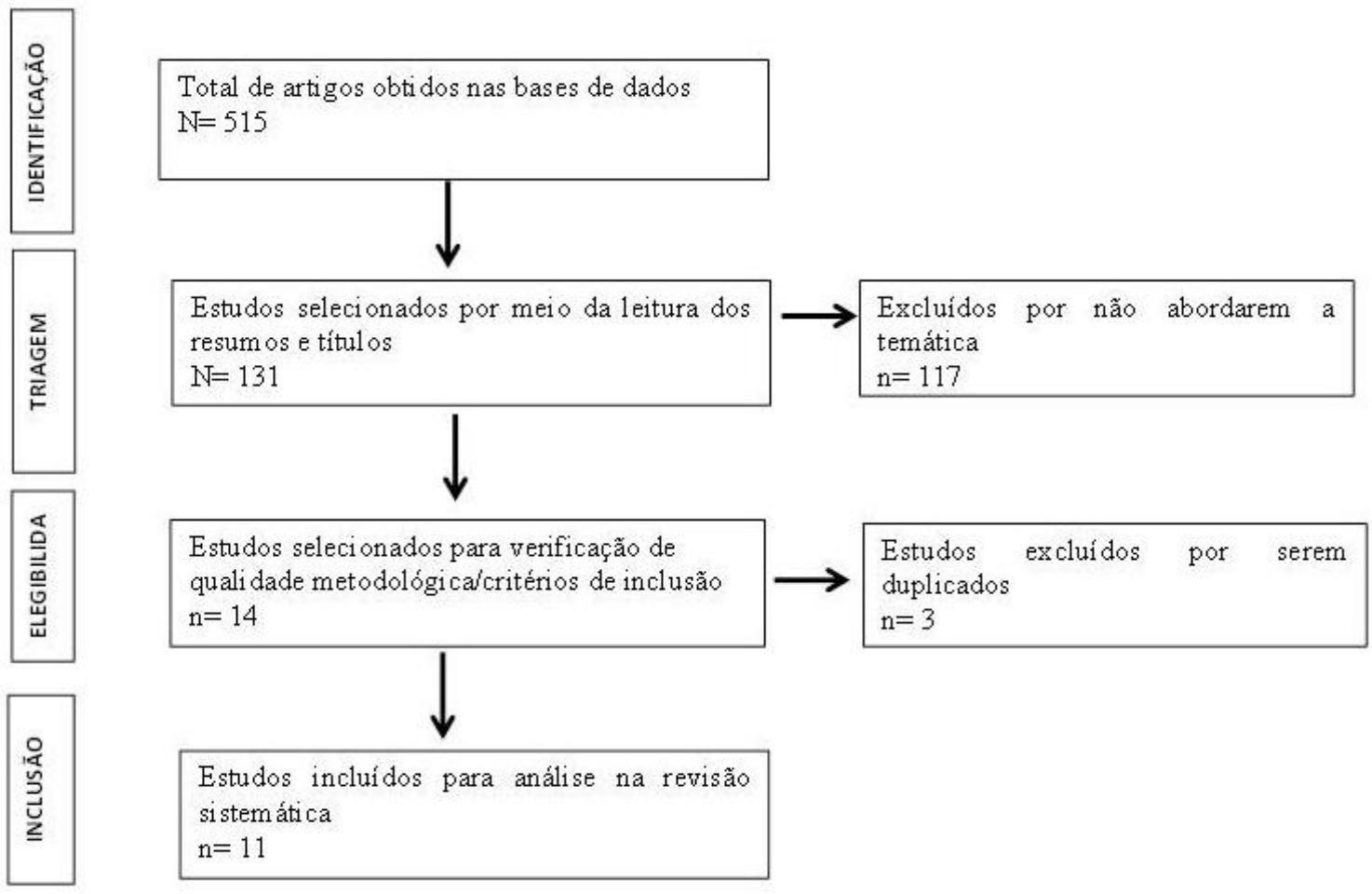

Figura I: Fluxograma da seleção de artigos da revisão sistemática.

$\mathrm{Na}$ Tabela 2 descreve-se o ano das publicações de 2000 - 2020 relacionados aos artigos selecionados na pesquisa para análise.

Quanto ao ano de publicação, foram localizados estudos publicados a partir de 20I0, mostrando que apesar de ser um tema em ascendência, ainda é relativamente novo. 
Em relação ao idioma dos estudos selecionados para a presente investigação, foram encontrados artigos publicados somente na língua inglesa conforme se pode observar na Tabela 3, que relaciona os periódicos onde as publicações foram localizadas.

Tabela 2: Distribuição dos artigos conforme os anos de publicação entre 2000 e 2020

\begin{tabular}{|c|c|c|}
\hline Ano & Número & Percentual \% \\
\hline 2010 & I & $9,1 \%$ \\
\hline $201 \mathrm{II}$ & 2 & $\mathrm{I} 8, \mathrm{I} \%$ \\
\hline 2012 & I & $9,1 \%$ \\
\hline 2013 & I & $9, \mathrm{I} \%$ \\
\hline 2014 & - & - \\
\hline 2015 & 2 & $\mathrm{I} 8, \mathrm{I} \%$ \\
\hline 2016 & I & $9, \mathrm{I} \%$ \\
\hline 2017 & - & - \\
\hline 2018 & I & $9, \mathrm{I} \%$ \\
\hline 2019 & I & $9, \mathrm{I} \%$ \\
\hline 2020 & I & $9,1 \%$ \\
\hline
\end{tabular}

Fonte: elaborado pela autora

Tabela 03 - Distribuição dos periódicos da amostra do estudo

\begin{tabular}{|l|c|c|}
\hline Nome do periódico & Número & Percentual (\%) \\
\hline Forensic Science International & 9 & $8 \mathrm{I}, 8 \%$ \\
\hline Revista Genomics Human Genet & I & $9,1 \%$ \\
\hline $\begin{array}{l}\text { International Journal of Law and } \\
\text { Psychiatry }\end{array}$ & I & $9,1 \%$ \\
\hline
\end{tabular}

Fonte: elaborado pela autora

Pode-se verificar que o tema é muito pertinente para a área da genética forense $e$ para a biologia enquanto área do conhecimento que vem ampliando sua inserção profissional nestes espaços. No entanto, observou-se que apesar de haver uma escassez de 
publicações, não foram identificadas investigações em periódicos da biologia, uma vez que a maioria dos estudos foi publicada no periódico (Forensic Science International).

Quanto aos aspectos metodológicos utilizados nos estudos analisados, revelou-se predominância de estudos quantitativos, compreendendo pesquisas do tipo: quase experimental ( $A_{1}, A_{2}, A_{9}$, Aro e $A_{11}$ ) e transversal retrospectivo ( $A_{3}, A_{4}, A_{7}$ e $A 8$ ). Apenas dois estudos utilizaram-se da pesquisa qualitativa do tipo estudo de caso (As e A6).

Uma síntese dos principais achados dos estudos analisados é apresentada no quadro I. As informações foram organizadas a partir das variáveis: título do estudo, autores, ano de publicação, periódico, objetivo do estudo, metodologia, resultados e considerações finais. Os artigos foram identificados por ordem numérica, precedidos da letra A (artigo).

\section{DISCUSSÃO}

A análise dos dados do presente estudo permitiu observar que as investigações publicadas abordaram a temática do uso de material genético na investigação e elucidação de crimes contra a vida em diferentes contextos e cenários. Os estudos de $\mathrm{A}_{1}, \mathrm{~A}_{7}$ e $\mathrm{A}_{9}$ denotaram investigações de casos de violência sexual envolvendo a vítima e o agressor (BOUZGA, VALKVAE, MEVAAG, 2013; FONNELØP et al., 2019; RAMOS, HANDTA, TAYLOR, 2020). Em A2, A8 e Aro os pesquisadores buscaram avaliar a presença de DNA em amostras de unhas em casos criminais que compreenderam homicídios e situações de agressão (BOZZO et al., 20I5; NURIT et al., 20Io; MATTE et al., 2012). Ainda estudo de $\mathrm{A}_{3}$ versa sobre a análise de DNA na investigação para liberação de vítimas com condenações injustas (HAMPIKIAN, WEST, AKSELROD, 20II). Já na perspectiva de abertura de casos de crimes não resolvidos a pesquisa realizada por Caglià, Stefanoni, La Rosa (2011) em A6 avalia casos que poderiam ser solucionados a partir de novas hipóteses investigativas e amostras biológicas não analisadas.

$\mathrm{Em} \mathrm{A}_{4}$ os autores investigam o uso da genética forense comportamental em processos criminais como o caso do genótipo MAOA-L. O estudo compreendeu a análise documental de casos que fizeram menção ao gene MAOA-L na investigação de crimes (MCSWIGGAN, ELGER, APPELBAU, 20I6). O artigo de A5 utiliza o padrão tri-alélico 
de curtas repetições para identificar o culpado em casos de assassinato envolvendo gêmeos monozigóticos (WANG et al., 2015) e por fim Air estuda marcadores de metilação de DNA dependentes da idade em diferentes tecidos por sequenciamento paralelo massivo e investiga se os 13 Loci previamente selecionados com base na análise de sangue total, incluindo, ELOVL2, TRIM59, F5 e KLFi4 também têm valor preditivo em outros tecidos forenses relevantes em casos de pessoas falecidas (NAUEA et al., 2018). 
Quadro sinóptico I

\begin{tabular}{|c|c|c|c|c|c|c|}
\hline Artigo & $\begin{array}{l}\text { Autores/ } \\
\text { Ano }\end{array}$ & Título/Periódico & Objetivo & Metodologia & Resultados & Considerações finais \\
\hline AI & $\begin{array}{l}\text { Bouzga, } \\
\text { Valkvae, } \\
\text { Mevaag, } \\
2013 \text {. }\end{array}$ & $\begin{array}{l}\text { Um caso de } \\
\text { estupro com } \\
\text { vários abusadores } \\
\text { desconhecidos. } \\
\text { Forensic Science } \\
\text { International }\end{array}$ & $\begin{array}{l}\text { Investigar o } \\
\text { padrão de } \\
\text { distribuição de } \\
\text { espermatozoides } \\
\text { em uma mancha. }\end{array}$ & $\begin{array}{l}\text { Quase } \\
\text { experimental } \\
\mathrm{N}: 60 \text { amostras ( } 9 \\
\text { amostras de } \\
\text { investigação de } \\
\text { rotina e 5I para } \\
\text { fins de pesquisa). }\end{array}$ & $\begin{array}{l}\text { Observaram-se misturas } \\
\text { complexas de DNA, com } \\
\text { pelo menos três e/ou quatro } \\
\text { envolvidos, em diferentes } \\
\text { proporções de mistura. } \\
\text { A amostragem se mostrou } \\
\text { essencial e a distribuição dos } \\
\text { espermatozóides não foi } \\
\text { uniformemente distribuída } \\
\text { ao longo da mancha. }\end{array}$ & $\begin{array}{l}\text { O teste presuntivo } \\
\text { produziu reações } \\
\text { positivas em todas as } \\
\text { amostras. } \\
\text { Recomenda-se } \\
\text { selecionar várias } \\
\text { amostras de coloração } \\
\text { em casos com vários } \\
\text { abusadores em } \\
\text { resultados de DNA } \\
\text { complexos. }\end{array}$ \\
\hline
\end{tabular}

11 


\begin{tabular}{|c|c|c|c|c|c|c|}
\hline $\mathrm{A}_{2}$ & $\begin{array}{l}\text { Bozzo et al. } \\
2015\end{array}$ & $\begin{array}{l}\text { Análise de DNA } \\
\text { de amostras de } \\
\text { unhas em casos } \\
\text { criminais. } \\
\text { Forensic Science } \\
\text { International }\end{array}$ & $\begin{array}{l}\text { Avaliar a } \\
\text { prevalência de } \\
\text { DNA encontrado } \\
\text { sob a unha em 7I } \\
\text { casos. }\end{array}$ & $\begin{array}{l}\text { Quase } \\
\text { experimental } \\
\text { N: } 164 \text { amostras de } \\
\text { unha coletadas } \\
\text { na operação de } \\
\text { autópsia em } \\
\text { homicídio. }\end{array}$ & $\begin{array}{l}\text { Das i64 amostras de unhas } \\
\text { analisadas, em } 74,6 \% \text { dos } \\
\text { casos foi encontrado um } \\
\text { perfil de DNA que } \\
\text { correspondia às vítimas e } \\
\text { dentro deste grupo em 13,2\% } \\
\text { havia um perfil de DNA } \\
\text { estranho. }\end{array}$ & $\begin{array}{l}\text { A prevalência estimada } \\
\text { em amostras de DNA } \\
\text { sob as unhas é } \\
\text { comparável com o } \\
\text { encontrado em triagens } \\
\text { de doadores voluntários. } \\
\text { O material encontrado } \\
\text { sob as unhas pode ser } \\
\text { importante para } \\
\text { comprovar qualquer tipo } \\
\text { de contato entre os } \\
\text { indivíduos. }\end{array}$ \\
\hline
\end{tabular}




\begin{tabular}{|c|c|c|c|c|c|c|}
\hline & & Human Genet & $\begin{array}{l}\text { de condenação } \\
\text { injusta. }\end{array}$ & \begin{tabular}{|l} 
criminosos). \\
.
\end{tabular} & $\begin{array}{l}\text { As evidências que } \\
\text { inocentaram os suspeitos } \\
\text { incluíram esfregaços íntimos } \\
(65 \%) \text {, roupas ( } 53 \%) \text {, cabelo } \\
(13 \%) \text {, evidências de unhas } \\
(5 \%) \text {, cigarros (3\%), entre } \\
\text { outras. O fator mais comum } \\
\text { associado a condenações } \\
\text { errôneas foram identificação } \\
\text { incorreta (75\%), incluindo } \\
\text { identificação incorreta pela } \\
\text { vítima (65\%) e falsas } \\
\text { confissões (30\%) dos casos. } \\
\text { Vários tipos de testemunhos } \\
\text { científicos foł̣nses inválidos } \\
\text { foram usados para condenar } \\
\text { injustamente I46 }\end{array}$ & criminosos. \\
\hline
\end{tabular}




\begin{tabular}{|c|c|c|c|c|c|c|}
\hline & & & & & $\begin{array}{l}\text { julgamentos. } \\
\text { Estes incluíram sorologia } \\
(38 \%) \text {, comparação de cabelo } \\
(22 \%) \text {, comparação de } \\
\text { impressão digital (2\%), e } \\
\text { comparação de marca de } \\
\text { mordida }(3 \%) \text {. }\end{array}$ & \\
\hline $\mathrm{A}_{4}$ & $\begin{array}{l}\text { Mcswiggan } \\
\text { Elger, } \\
\text { Appelbau, } \\
\text { 2016. }\end{array}$ & $\begin{array}{l}\text { O uso da } \\
\text { genética forense } \\
\text { comportamental } \\
\text { em processos } \\
\text { criminais: o caso } \\
\text { do genótipo } \\
\text { MAOA-L. } \\
\text { International } \\
\text { Journal of Law } \\
\text { and Psychiatry }\end{array}$ & $\begin{array}{l}\text { Identificar } \\
\text { documentos } \\
\text { judiciais de } \\
\text { processo penal } \\
\text { com referência ao } \\
\text { genótipo MAOA- } \\
\text { L no período de } \\
\text { I995 a 20I6 nos } \\
\text { bancos de dados } \\
\text { jurídicos Westlaw }\end{array}$ & $\begin{array}{l}\text { Estudo transversal } \\
\text { retrospectivo } \\
\text { N:II } \\
\text { processos } \\
\text { criminais (9 nos } \\
\text { EUA e } 2 \text { na Itália). }\end{array}$ & $\begin{array}{l}\text { Na fase de culpa, a evidência } \\
\text { do genótipo MAOA-L foi } \\
\text { considerada em um dos dois } \\
\text { casos, e pode ter contribuído } \\
\text { para uma condenação em } \\
\text { uma acusação menor. Na } \\
\text { fase de condenação, a } \\
\text { evidência dd4 genótipo foi } \\
\text { admissível em quatro dos } \\
\text { cinco casos, um dos quais }\end{array}$ & $\begin{array}{l}\text { Mesmo quando } \\
\text { acusações ou sentenças } \\
\text { são reduzidas é difícil } \\
\text { avaliar o efeito da } \\
\text { evidência do genótipo } \\
\text { MAOA-L. Pode faltar } \\
\text { evidência do efeito } \\
\text { persuasivo do genótipo } \\
\text { porque o impacto do } \\
\text { alelo em um acusado em }\end{array}$ \\
\hline
\end{tabular}




\begin{tabular}{|c|c|c|c|c|c|c|}
\hline & & & e LexisNexis. & & $\begin{array}{l}\text { terminou com uma pena } \\
\text { menor. Cinco casos usaram } \\
\text { evidência do genótipo para } \\
\text { recursos pós-condenação, } \\
\text { dois dos quais resultaram em } \\
\text { redução de pena. }\end{array}$ & $\begin{array}{l}\text { particular é difícil de ser } \\
\text { estabelecido. }\end{array}$ \\
\hline
\end{tabular}




\begin{tabular}{|c|c|c|c|c|c|c|}
\hline & & $\begin{array}{l}\text { Forensic Science } \\
\text { International: } \\
\text { Genetics }\end{array}$ & & & $\begin{array}{l}\text { observar que gêmeos } \\
\text { idênticos podem ter padrões } \\
\text { diferentes de mutação (I6, I8 } \\
\text { e 19). }\end{array}$ & $\begin{array}{lr}\text { como formas } \\
\text { independentes, } \\
\text { interconectadas, } \\
\text { mutação STR. }\end{array}$ \\
\hline A6 & $\begin{array}{l}\text { Caglià, } \\
\text { Stefanoni, } \\
\text { La Rosa, } \\
\text { 2OII }\end{array}$ & $\begin{array}{l}\text { Casos } \\
\text { arquivados: } \\
\text { Novas } \\
\text { tecnologias para } \\
\text { análise de DNA } \\
\text { permitem a } \\
\text { reabertura e } \\
\text { solução de casos } \\
\text { não resolvidos. } \\
\text { Forensic Science } \\
\text { International: } \\
\text { Genetics }\end{array}$ & $\begin{array}{l}\text { Avaliar quais } \\
\text { casos não } \\
\text { resolvidos } \\
\text { poderiam ser } \\
\text { selecionados em } \\
\text { relação a novas } \\
\text { hipóteses } \\
\text { investigativas e na } \\
\text { presença de } \\
\text { amostras } \\
\text { biológicas não } \\
\text { analisadas. }\end{array}$ & $\begin{array}{l}\text { Estudo de caso } \\
\mathrm{N}: 30 \text { casos }\end{array}$ & $\begin{array}{l}\text { A automação dos processos } \\
\text { de extração de DNA, } \\
\text { combinados com os kits de } \\
\text { PCR de última geração, } \\
\text { possibilitou resultados } \\
\text { positivos também em } \\
\text { manchas antes consideradas } \\
\text { não permitidas. Em oito } \\
\text { casos, a análise de DNA } \\
\text { levou à identificação de um } \\
\text { ou mais perfiłgenéticos que } \\
\text { são considerados de grande } \\
\text { interesse do ponto de vista }\end{array}$ & $\begin{array}{l}\text { A análise microscópica } \\
\text { de DNA em traços, ou } \\
\text { nas células epiteliais } \\
\text { produziram resultados } \\
\text { surpreendentemente } \\
\text { positivos, mesmo em } \\
\text { amostras anteriormente } \\
\text { consideradas negativas. } \\
\text { Nos últimos anos, as } \\
\text { investigações científicas, } \\
\text { ao lado de métodos } \\
\text { tradicionais de } \\
\text { investigação }\end{array}$ \\
\hline
\end{tabular}




\begin{tabular}{|c|c|c|c|c|c|c|}
\hline & & & & & $\begin{array}{l}\text { investigativo, permitindo a } \\
\text { identificação dos assassinos } \\
\text { em três situações diferentes. }\end{array}$ & $\begin{array}{l}\text { internacionais, como } \\
\text { suas melhorias } \\
\text { tecnológicas e analíticas } \\
\text { relativas tornaram-se } \\
\text { cada vez mais decisivos } \\
\text { para a resolução de } \\
\text { processos judiciais. }\end{array}$ \\
\hline $\mathrm{A}_{7}$ & $\begin{array}{l}\text { Fonneløp et } \\
\text { al. } 2019\end{array}$ & 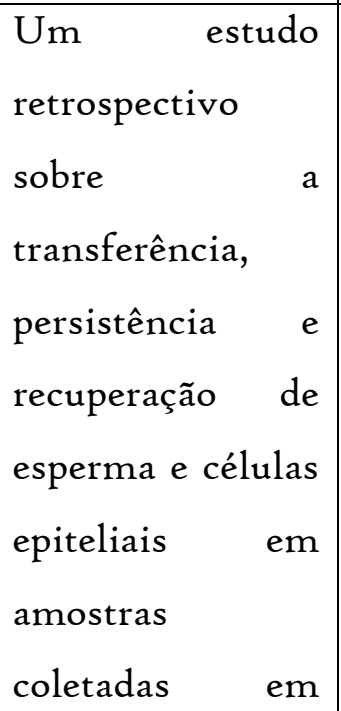 & $\begin{array}{l}\text { Analisar dados de } \\
\text { um estudo } \\
\text { retrospectivo de } \\
\text { casos de agressão } \\
\text { sexual, no período } \\
\text { 2013-2015. }\end{array}$ & $\begin{array}{l}\text { Estudo transversal } \\
\text { retrospectivo N: } \\
2349 \text { amostras (766 } \\
\text { casos) }\end{array}$ & $\begin{array}{l}\text { Células de espermatozoides } \\
\text { foram detectadas em } \\
\text { amostras vaginais internas } \\
\text { coletadas até } 72 \mathrm{~h} \text { após a } \\
\text { agressão, sendo encontrados } \\
\text { com menor frequência em } \\
\text { swabs orais, onde o tempo } \\
\text { de constattação mais } \\
\text { prolongado foi de I2 horas. } \\
\text { Resultados positivos de }\end{array}$ & $\begin{array}{l}\text { Os resultados do estudo } \\
\text { podem contribuir como } \\
\text { guia de prioridade na } \\
\text { escolha de amostras para } \\
\text { análise, dependendo do } \\
\text { tempo entre a agressão } \\
\text { sexual e o exame médico } \\
\text { da vítima ou suspeito. }\end{array}$ \\
\hline
\end{tabular}




\begin{tabular}{|c|c|c|c|c|c|c|}
\hline & & $\begin{array}{l}\text { casos de } \\
\text { violência sexual. } \\
\text { Forensic Science } \\
\text { International: } \\
\text { Genetics }\end{array}$ & & & $\begin{array}{l}\text { análise das células epiteliais } \\
\text { foram observados até } 43 \\
\text { horas após o ato. Uma alta } \\
\text { taxa de sucesso foi } \\
\text { observada a partir de swabs } \\
\text { penianos coletados dentro de } \\
24 \text { horas da ocorrência, } \\
\text { demonstrando a importância } \\
\text { da coleta e análise desta } \\
\text { amostra nos casos em que } \\
\text { nenhum sêmen é } \\
\text { encontrado. }\end{array}$ & \\
\hline
\end{tabular}




\begin{tabular}{|c|c|c|c|c|c|c|}
\hline & & $\begin{array}{l}\text { amostras de } \\
\text { unhas de vítimas } \\
\text { e suspeitos em } \\
\text { casos de } \\
\text { homicídio. } \\
\text { Forensic Science } \\
\text { International: } \\
\text { Genetics }\end{array}$ & $\begin{array}{ll}\text { supostos } & \text { autores } \\
\text { de } & \text { mortes } \\
\text { violentas. } & \end{array}$ & $\begin{array}{l}\text { unhas de vítimas e } \\
\text { suspeitos de } \\
\text { homicídio. }\end{array}$ & 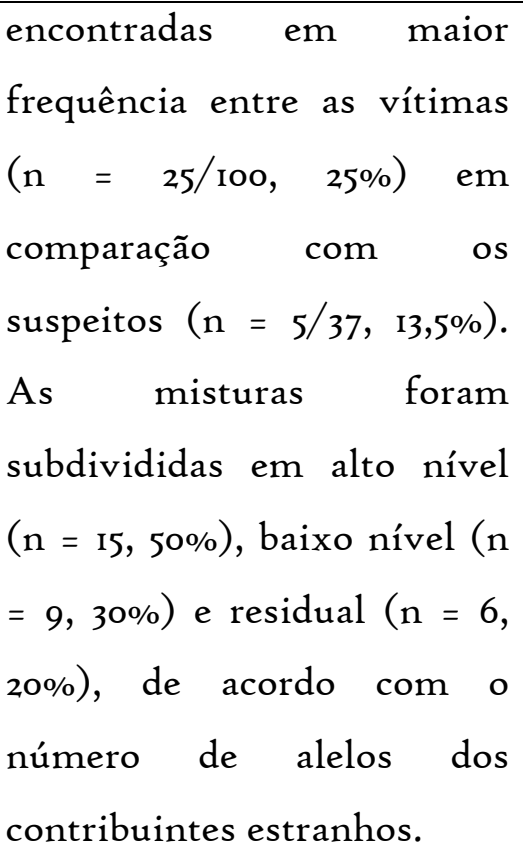 & $\begin{array}{l}\text { um perfil adicional pode } \\
\text { apontar para um } \\
\text { possível autor do crime. } \\
\text { Assim, valor } \\
\text { evidenciado das } \\
\text { misturas de DNA, } \\
\text { proveniente de amostras } \\
\text { de unha da vítima ou } \\
\text { suspeito, pode ser uma } \\
\text { ferramenta valiosa em } \\
\text { uma investigação de } \\
\text { homicídio. }\end{array}$ \\
\hline $\mathrm{A}_{9}$ & $\begin{array}{l}\text { Ramos, } \\
\text { Handta, } \\
\text { Taylor, } \\
2020\end{array}$ & $\begin{array}{l}\text { Investigar a } \\
\text { posição e o nível } \\
\text { de transferência } \\
\text { de DNA para } \\
\text { roupas íntimas }\end{array}$ & $\begin{array}{l}\text { Determinar a } \\
\text { estratégia de } \\
\text { amostragem ideal } \\
\text { em roupas íntimas; } \\
\text { Investigar quanto }\end{array}$ & $\begin{array}{l}\text { Estudo } \\
\text { experimental } \\
\text { N: i2 pessoas ( } 8 \\
\text { mulheres e } 4 \\
\text { homens). }\end{array}$ & $\begin{array}{l}\text { Foram examinados seis } \\
\text { cenários de agressão sexual; } \\
\text { remoção da 19oupa íntima, } \\
\text { remoção do sutiã, penetração } \\
\text { digital da vagina pela frente, }\end{array}$ & $\begin{array}{l}\text { Os resultados obtidos } \\
\text { ajudarão } \\
\text { identificação de áreas } \\
\text { para direcionar roupas } \\
\text { íntimas para diferentes }\end{array}$ \\
\hline
\end{tabular}




\begin{tabular}{|c|c|c|c|c|c|}
\hline & & $\begin{array}{l}\text { durante agressão } \\
\text { sexual digital. } \\
\text { Forensic Science } \\
\text { International: } \\
\text { Genetics }\end{array}$ & $\begin{array}{l}\text { DNA foi } \\
\text { transferido } \\
\text { explorar } \\
\text { quantidade de } \\
\text { DNA de um } \\
\text { parceiro coabitante } \\
\text { de um dos } \\
\text { criminosos } \\
\text { conhecidos } \\
\text { que foi transferido } \\
\text { quando o agressor } \\
\text { tocou nas roupas } \\
\text { íntimas. }\end{array}$ & $\begin{array}{l}\text { toque aos seios por cima do } \\
\text { sutiã, penetração digital da } \\
\text { vagina por trás e toque aos } \\
\text { seios sob o sutiã pela parte } \\
\text { posterior. } \\
\text { Identificou-se que a } \\
\text { quantidade de DNA } \\
\text { encontrada depende de qual } \\
\text { indivíduo agiu como } \\
\text { agressor e sugere que este } \\
\text { depende do nível da } \\
\text { agressão. Igualmente, foi } \\
\text { encontrado material de } \\
\text { DNA do cônjuge ou colega } \\
\text { de trabalho elø agressor na } \\
\text { roupa íntima. }\end{array}$ & $\begin{array}{lr}\text { cenários de } & \text { agressão } \\
\text { sexual e } & \text { também } \\
\text { fornecerá } & \text { informações } \\
\text { importantes que podem } \\
\text { ser usadas } & \text { para } \\
\text { atribuição } & \text { de } \\
\text { probabilidades } & \text { de } \\
\text { transferência de } & \text { DNA } \\
\text { auxiliando avaliações de } \\
\text { descobertas da } & \text { biologia } \\
\text { forense. }\end{array}$ \\
\hline
\end{tabular}




\begin{tabular}{|c|c|c|c|c|c|c|}
\hline Aro & $\begin{array}{l}\text { Matte et al. } \\
2012\end{array}$ & $\begin{array}{l}\text { Prevalência e } \\
\text { persistência de } \\
\text { DNA estranho } \\
\text { sob as unhas. } \\
\text { Forensic Science } \\
\text { International: } \\
\text { Genetics }\end{array}$ & $\begin{array}{l}\text { Fornecer à } \\
\text { comunidade } \\
\text { forense dados } \\
\text { sobre a } \\
\text { importância da } \\
\text { evidência de DNA } \\
\text { na unha para usar } \\
\text { na formação de } \\
\text { pareceres. }\end{array}$ & $\begin{array}{l}\text { Estudo Quase } \\
\text { experimental. } \\
\mathrm{N}: 265 \text { amostras de } \\
\text { unha }\end{array}$ & $\begin{array}{l}\text { Das } 265 \text { amostras de unha, } \\
33 \% \text { continham uma fonte } \\
\text { estranha de DNA. Em uma } \\
\text { amostra de unhas na } \\
\text { população em geral, I9\% } \\
\text { continham uma fonte } \\
\text { estranha de DNA. Em um } \\
\text { estudo envolvendo a prática } \\
\text { de arranhar outro indivíduo, } \\
33 \% \text { dos indivíduos tinham } \\
\text { um perfil de DNA estranho } \\
\text { abaixo de suas unhas das } \\
\text { quais a pessoa que foi } \\
\text { arranhada não pode ser } \\
\text { excluída comor fonte; após } 6 \\
\text { h do evento de arranhar, } \\
\text { apenas } 7 \% \text { retiveram DNA }\end{array}$ & $\begin{array}{l}\text { Há um aumento da } \\
\text { prevalência de DNA } \\
\text { estranho detectado sob } \\
\text { as unhas onde o } \\
\text { histórico do caso inclui } \\
\text { contato próximo entre o } \\
\text { agressor e a vítima. A } \\
\text { baixa incidência de } \\
\text { DNA estranho em uma } \\
\text { amostra após a prática } \\
\text { deliberada de arranhar } \\
\text { sugere que é necessário } \\
\text { mais do que apenas o } \\
\text { contato casual para que } \\
\text { DNA estranho seja } \\
\text { retido e que geralmente } \\
\text { não persistirá por longos }\end{array}$ \\
\hline
\end{tabular}




\begin{tabular}{|c|c|c|c|c|c|c|}
\hline & & & & & estranho sob as unhas. & períodos. \\
\hline AII & $\begin{array}{l}\text { Nauea et al, } \\
2018\end{array}$ & $\begin{array}{l}\text { Estudo de prova } \\
\text { de conceito de } \\
\text { marcadores de } \\
\text { metilação de } \\
\text { DNA } \\
\text { dependentes da } \\
\text { idade em } \\
\text { diferentes tecidos } \\
\text { por } \\
\text { sequenciamento } \\
\text { paralelo massivo. } \\
\text { Forensic Science } \\
\text { International: } \\
\text { Genetics }\end{array}$ & 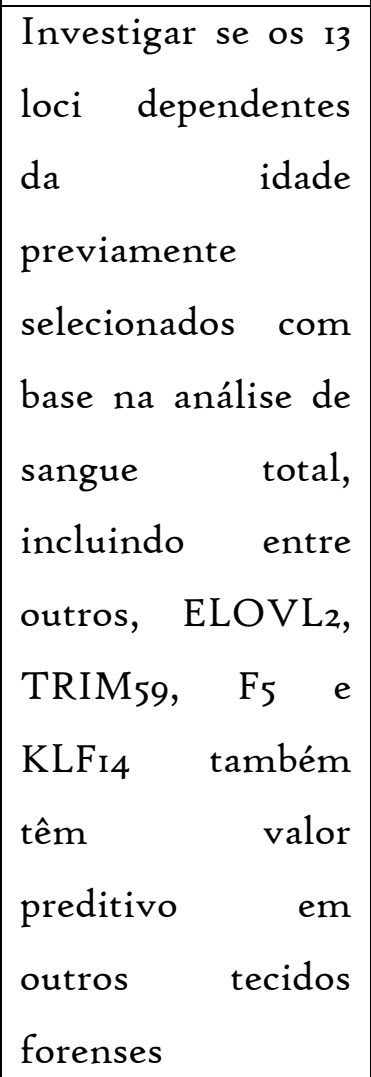 & $\begin{array}{l}\text { Estudo quase } \\
\text { experimental } \\
\mathrm{N}: 29 \text { pessoas } \\
\text { falecidas }\end{array}$ & $\begin{array}{l}\text { Amostras de cérebro, osso, } \\
\text { músculo, esfregaços bucais e } \\
\text { sangue total de } 29 \text { pessoas } \\
\text { falecidas (faixa etária de o a } \\
87 \text { anos) foram analisados } \\
\text { para esses i3 marcadores } \\
\text { dependentes da idade usando } \\
\text { sequenciamento paralelo. } \\
\text { Sete desses loci mostraram } \\
\text { dependência da idade em } \\
\text { todos os cinco tecidos. A } \\
\text { Mudança de DNAm (DNA } \\
\text { mitocondrial) } 22 \text { durante a vida } \\
\text { foi diferente no conjunto de } \\
\text { tecidos analisados. }\end{array}$ & $\begin{array}{l}\text { O estudo apresenta o } \\
\text { potencial } \\
\text { marcadores de DNAm } \\
\text { existentes no sangue } \\
\text { para determinação da } \\
\text { idade para analisar } \\
\text { outros tecidos além do } \\
\text { sangue. } \\
\text { identificados sete } \\
\text { marcadores de DNAm } \\
\text { (DDO, ELOVL2, } \\
\text { KLFi4, NKIRAS, RPA2, } \\
\text { TRIM59 e ZYGIIA) } \\
\text { baseados no sangue } \\
\text { conhecidos para uso em }\end{array}$ \\
\hline
\end{tabular}


${ }_{\text {oPEN }} \widehat{\odot}_{\text {ACCESS }}$

\begin{tabular}{|l|l|l|l|l|}
\hline & & relevantes. & & \\
& & & $\begin{array}{l}\text { músculos, cérebro, } \\
\text { ossos, saliva e sangue. } \\
\text { entanto, um } \\
\text { No } \\
\text { conjunto de referências } \\
\text { diferentes para cada } \\
\text { tecido se faz necessário } \\
\text { para adaptar às } \\
\text { mudanças específicas de } \\
\text { secido do DNAm ao } \\
\text { Dengo do tempo. }\end{array}$ \\
\hline
\end{tabular}

Elaborado pela autora. 
O estudo quase experimental de Ar, realizado na Noruega com 60 amostras de material, submetidas a testes de Fosfatase Ácida (Brentamina teste) e microscopia para confirmar a presença de espermatozoides dos envolvidos em caso de estupro, mostrou que o teste presuntivo com fosfatase ácida produziu reações positivas em todas as amostragens, sugerindo a utilização de várias técnicas de coloração na investigação de crimes que envolvem vários abusadores com amostras de DNA complexo. O estudo mostrou ainda que a distribuição dos espermatozoides não ocorreu de forma uniforme ao longo de uma mancha, o que justifica a utilização de diversas amostragens (BOUZGA, VALKVAE, MEVAAG, 2013). Neste contexto, estudo realizado na Dinamarca por Westring et al., (2014) com amostras de vítimas de agressão sexual utilizando dois métodos de microscopia fluorescente (Sperm Hylitertm, e o método de Baecchi), demonstrou que o Sperm Hy-litertm foi mais eficaz, além de ser mais específico para espermatozoides humanos, enquanto o método de Baecchi não diferenciou entre esperma humano e não humano.

Em consonância com esta temática, outro estudo norueguês com 2349 amostras envolvendo 766 casos de agressão sexual, realizada por Fonneløp et al., (2019) em $\mathrm{A}_{7}$, que analisou dados relativos à transferência, permanência $\mathrm{e}$ recuperação de espermatozóide e células epiteliais em amostras coletadas em casos de violência sexual identificou que células espermáticas foram encontradas em amostras vaginais coletadas até 72 horas após a agressão e com menor frequencia em swabs orais em até 12 horas. Já a presença de células epiteliais foi observada até 43 horas após o ato. Ainda em A9, investigação de Ramos, Handta, Taylor (2020) realizada na Austrália, com 12 pessoas, se ocupou em identificar as áreas das roupas íntimas com maior contato em casos de agressão sexual, utilizando seis cenários diferentes de simulação. O estudo concluiu que as áreas alvo para investigação são os lados das roupas intimas e que há pouca diferença quanto às superfícies interna e externa destas, sugerindo amostragens separadas.

Convergindo com os achados mencionados anteriormente, estudo brasileiro conduzido por Paulino, Conceição e Decanine (2017) no Mato Grosso do Sul que analisou 895 laudos buscando observar a presença de vestígios de esperma nas 
vestimentas e nas coletas de swab de vítimas de estupro, identificou que os exames realizados apenas nas vestes foram estatisticamente mais significativos comparado à coleta de material por swab, sugerindo que, juntamente com as vestes das vítimas, contribui para a resolução do caso. No entanto, em casos de crimes sexuais, recomenda-se a realização do exame de corpo de delito e apresentação das vestes do momento da agressão. Neste sentido, o DNA é utilizado para elucidação de crimes contra a vida, através de vestígios biológicos que o estuprador acaba deixando na vítima, como espermatozoides, linfócitos, células do pênis, do escroto, dos dedos, saliva, entre outros (PAES, RIBEIRO, 2016).

Da mesma forma, a presença de DNA em amostras de unhas para investigação de casos criminais envolvendo homicídio foi pesquisado na Argentina por Bozzo et al., (2015), em A2, com 164 amostras de unhas de vítimas e agressores coletadas através da extração, corte e esfregaço realizados durante o procedimento de autópsia. O estudo mostrou uma prevalência de 74,6\% dos casos analisados com perfil de DNA correspondente às vítimas, sendo que deste grupo 13,2\% apresentaram um segundo perfil de DNA presente, comprovando a importância do material encontrado sob as unhas na investigação e elucidação de casos de violência ou contato entre vítima e agressor. Nesta direção, investigação israelense realizada por Nurit et al., (20II) em A8, com 137 perfis de DNA genotipados de amostras de unhas de vítimas e suspeitos de homicídio foram avaliados quanto a prevalência de misturas do material encontrado sob as unhas dos envolvidos, sendo que $78 \%$ das amostras produziram perfis de fonte única de doadores e $22 \%$ compreenderam misturas de DNA envolvendo na sua maioria as vítimas. Portanto, a identificação de um perfil adicional encontrado em uma mistura de amostra de unha pode apontar para um possível autor do crime e contribuir na investigação criminal em casos onde possa ter ocorrido uma luta entre a vítima e o agressor ou através de pesquisa em banco de dados de DNA. Do mesmo modo, estudo quase experimental conduzido por pesquisadores canadenses em Aro envolvendo 265 amostras de unha observaram aumento da prevalência de DNA estranho sob as unhas em casos de contato entre agressor e vítima e conclui a necessidade de um contato mais do que casual para que 
seja possível adquirir e reter DNA estranho sob as unhas (MATTE et al., 2012), reafirmando os resultados dos estudos anteriores e potencializando a contribuição do método na elaboração de pareceres técnicos.

Corroborando com os achados mencionados, estudo de caso denotado no Brasil por Frohlich et al., (2020) envolvendo homicídio de uma criança e a mãe, mostrou que a análise dos vestígios encontrados sob as unhas da mãe possibilitou identificar o culpado, sendo que o material genético do investigado apresentou 10o\% de compatibilidade com a evidência. Desta forma, a biologia forense através da análise do DNA compõe método de combate à criminalidade e à impunidade, podendo inocentar ou incriminar os envolvidos (ARAUJO, 2018; FINDLEY, 2013). Com esta prerrogativa, estudo de $\mathrm{A}_{3}$ analisou as evidências e testes de DNA que foram usados para libertar as vítimas de condenação injusta através de 194 exonerações de DNA relativos a I7I casos criminosos nos EUA, verificou que a análise de repetição curta em tandem (STR) prevaleceu em $70 \%$ dos casos e as evidências utilizadas para inocentar as vítimas compreenderam esfregaços íntimos $(65 \%)$, roupas $(53 \%)$, cabelo ( $13 \%)$, evidências de unhas ( $5 \%)$, cigarros (3\%), entre outros. A identificação incorreta em $75 \%$ dos eventos, incluindo aquela realizada pela vítima, entre outras evidências científicas forenses inválidas estiveram associadas às condenações injustas como comparação de cabelo e marca de mordida (HAMPIKIAN, WEST, AKSELROD, 20II). Por isso, o uso de tecnologias de DNA e a coleta de perfis genéticos para identificação criminal, em casos hediondos ou violentos e/ou em infrações não elucidadas, pode ser uma estratégia irrefutável na investigação e condenação de crimes como prevê a legislação brasileira, através da lei I2.654/12, (BRASIL, 2012a).

Considerando a análise de DNA, estudo italiano em A6 buscou analisar 30 casos arquivados e não resolvidos e verificou em oito destes casos um ou mais perfis genéticos de grande importância para a perícia técnica e análise investigativa, permitindo a identificação dos assassinos em três casos diferentes (Caglià, Stefanoni, La Rosa, 2011). Ainda, estudo de caso de Wang et al., (2015), em A5, identificou com exatidão gêmeos idênticos a partir do padrão tri-alélico de curtas repetições em 
tandem (STRs), podendo excluir o gêmeo inocente em uma acusação de assassinato envolvendo uma menina chinesa. Ao testar os 16 locus de STR projetados para asiáticos, pode comparar os perfis genéticos dos gêmeos homozigotos que se igualaram exceto pela existência de três bandas nos alelos locus vWA para o suspeito 2 em comparação a um padrão di-alélico para o suspeito I. O perfil do locus vWA no sêmen da cena do crime correspondente a amostra de sangue do suspeito I, sugeriu que esta mutação única exclui o suspeito 2 como o abusador. $O$ estudo indica que esta mutação ocorre após a formação do zigoto embrionário e posteriormente a divisão blastocística. A análise genética pode ser fundamental não somente para condenar, mas também para absolver inocentes que cumprem penas injustas. Conforme informações do consagrado “Innocence Project” nos Estados Unidos, 375 pessoas tiveram suas sentenças condenatórias revertidas a partir de provas de DNA, sendo que destas 2i cumpriam pena no “corredor da morte" (INNOCENCE PROJECT, sem data).

Pesquisa alemã, do tipo quase experimental realizada por Nauea et al., (2018) em Air com amostras de cérebro, osso, músculo, esfregaços bucais e sangue total de 29 pessoas falecidas com idade entre o a 87 anos foram analisados para 13 marcadores dependentes da idade, incluindo, ELOVL2, TRIM59, F5 e KLFI4. O estudo buscou conhecer se estes apresentavam valor preditivo em outros tecidos forenses relevantes e identificou sete marcadores de DNAm (DDO, ELOVL2, KLFi4, NKIRAS, RPA2, TRIM59 e ZYGIIA) baseados no sangue que são possíveis para uso nas amostras investigadas. Desta forma concluiu-se que os marcadores de DNAm existentes no sangue tem importante potencial para determinação da idade e análise de outros tecidos e que apesar de os marcadores selecionados apresentarem alterações em todos ou alguns tecidos analisados, o DMAm inicial no nascimento pode variar com as alterações no modo e estilo de vida (NAUEA et al., 2018). Neste sentido, outros estudos reforçam que a metilação sofre influência do próprio processo de envelhecimento, dietas e escolhas de vida e que a metilação do DNAm nas posições $\mathrm{CpG}$ no genoma humano tem sido amplamente potencializada na investigação de casos forenses (KADER, GHAI, 2015; GARALI et al., 2020). 
Outra estratégia que pode contribuir no processo de comprovação de crimes violentos é a ciência forense na genética comportamental, através da análise de variação alélica do gene monoamina-oxidase A (MAOA), responsável por catabolizar os neurotransmissores de amina, dopamina, serotonina e noradrenalina, embora os fatores ambientais e sociais possam atenuar o fator genético (SOHRABI, 2015). Nesta direção, estudo transversal liderado por Mcswiggan, Elger, Appelbau (2016) em $\mathrm{A}_{4}$, buscou identificar documentos judiciais de processo penal com referência ao genótipo de baixa atividade da enzima monoamina-oxidase (MAOAL) e evidenciou a inclusão do gene MAOA-L em II registros de casos criminais sendo 9 nos EUA e 2 na Itália. O estudo registrou que no processo de condenação, a evidência do genótipo foi utilizada em quatro de cinco casos, com uma redução de pena e em cinco recursos pós-condenação, com duas reduções de pena. No entanto, a investigação reforça que mesmo em situações de acusação ou sentença o efeito específico da evidência do genótipo MAOA-L é difícil de ser mensurado, corroborando com os achados do estudo anterior (MCSWIGGAN, ELGER, APPELBAU, 2016), assim como é potencializado em pesquisa americana realizada por Appelbaum, Scurich, Raad (2015).

\section{CONSIDERAÇÕES FINAIS}

O estudo permitiu verificar que a genética forense é uma área que se encontra em ascensão e a biologia molecular constitui ferramenta relevante na investigação de crimes contra a vida, na redução da impunidade e de condenações injustas.

O uso de material genético coletado na cena do crime ou através da análise de perfis tem permitido identificar com precisão autores de crimes de natureza grave, contribuindo assim na sua elucidação e para a perícia técnica. Neste sentido, a biologia vem ocupando espaço de atuação na esfera da criminalística de forma exponencial.

Novos estudos podem ser realizados no sentido de potencializar as evidências científicas e qualificar o processo investigativo e de condenações por crimes contra a 
vida no que tange a biologia molecular, o desenvolvimento e implementação de suas técnicas.

\section{REFERÊNCIAS}

APPELBAUM, Paul S. et al Effects of behavioral genetic evidence on perceptions of criminal responsibility and appropriate punishment. Psychology, Public Policy, and Law, 2I(2), I34-I44, março. 2015. Disponível em: https://www.ncbi.nlm.nih.gov/pmc/articles/PMC4521637/pdf/nihms-672233..

ARAUJO, Mikaelly Correia de. O DNA como ferramenta de identificação humana e a sua importância no trabalho da perícia criminal. 2018. 20 f. TCC (Graduação) Curso de Biomedicina, Centro Universitário Cesmac, Maceió, 2018. Disponível em: http://srv-bdtd:8o8o/handle/tede/r66.

BEZERRA, C.C. Exame de DNA: coleta de amostras biológicas em local de crime. Perícia Federal: DNA forense - técnicas de coleta em locais de crimes, n. I8, p. 6-I4, 2004 .

BONACCORSO, N. S. Aspectos técnicos, éticos e jurídicos relaciona dos com a criação de banco de dados criminais de DNA no Brasil. 2010. $276 \mathrm{f}$. Tese (Doutorado em Direito Penal), Faculdade de Direito. Universidade de São Paulo (USP), São Paulo, 2010. Disponível em: https://www.teses.usp.br/teses/disponiveis/2/2136/tde04102010-I41930/pt-br.php.

BOUZGA, M.; VALKVAE, K.L.; MEVAAG, B. A rape case with multiple unknown perpetrators. Forensic Science International: Genetics Supplement Series, [S.L.], v. 4, n. I, p. 362-363, 2013. Elsevier BV. http://dx.doi.org/ıo.1016/j.fsigss.2013.10.184. Disponível em: https://www.sciencedirect.com/science/article/abs/pii/Si875176813001856.

BOZZO, W.R et al. Analysis of DNA from fingernail samples in criminal cases. Forensic Science International: Genetics Supplement Series, [S.L.], v. 5, p. 6or-602, dez. 2015. Elsevier BV. http://dx.doi.org/ro.IoI6/j.fsigss.2015.09.237. Disponível

em: https://www.sciencedirect.com/science/article/abs/pii/S I87517681500o049.

BRASIL. Lei $\mathrm{n}$ - 12.654 , de 28 de maio de 2012. Altera as Leis de $\mathbf{n} \mathbf{0} \mathbf{1 2 . 0 3 7}$ de ro de outubro de 2009, e 7.210, de II de julho de 1984 - Lei de Execução Penal, para prever a coleta de perfil genético como forma de identificação criminal, e dá outras providências. Disponível em: http://www.planalto.gov.br/ccivil_03/_atozorI2014/2012/lei/li2654.htm

BRASIL. Ministério da Justiça. Lei no 12.853 de 14 de agosto de 2013. Brasília: Presidência da República. 
BRASIL. Ministério da Justiça. Lei no 9.61o de 19 de fevereiro de 1988 . Lei do direito autoral. Brasília: Diário Oficial da União, 1988.

BRASIL. Ministério da Saúde. Secretaria de Ciência, Tecnologia e Insumos Estratégicos. Departamento de Ciência e Tecnologia. Diretrizes metodológicas: elaboração de revisão sistemática e metanálise de ensaios clínicos randomizados/. Brasília: Editora do Ministério da Saúde, 2012. Disponível em: https://bvsms.saude.gov.br/bvs/publicacoes/diretrizes_metodologicas_elaboracao_si stematica.pdf

BRASÍLIA. Justiça e segurança pública. Banco Nacional de Perfis Genéticos: uma ferramenta eficiente para elucidação de crimes. 2019. Disponível em: https://www.justica.gov.br/news/collective-nitf-content-1556212211.45

BROWN, T.A. Clonagem Gênica e Análise de DNA: Uma introdução. 4.ed. Porto Alegre: Artmed. 200I. p.376.

CAGLIÀ, A.; STEFANONI, P.; LAROSA, A. Cold cases: new technologies for dna analysis allow the reopening and solution of unsolved cases. Forensic Science International: Genetics Supplement Series, [S.L.], v. 3, n. I, p. 230-231, dez. 2011. Elsevier BV. http://dx.doi.org/ro.roI6/j.fsigss.2011.09.0or. Disponível em: https://www.sciencedirect.com/science/article/abs/pii/Si875176811001168.

DIAS FILHO, Claudemir Rodrigues et al (org.). Introdução a Genética forense. São Paulo: Millennium, 2020. $632 \mathrm{p}$.

DOLINSKY, Luciana Cresta; PEREIRA, Lissiane Miranda Campelo Veras. DNA Forense Artigo de Revisão. Saúde e Ambiente em Revista, Universidade do Grande Rio - Unigranrio/ Duque de Caxias, v. 2, n. 2, p. II-22, Io jun. 2007. Disponível em: https://www.biologia.bio.br/curso/2\%C2\%BA\%2oper\%C3\%ADodo\%2oFaciplac/Ge n\%C3\%A9tica/DNA\%2oforense_artigo\%2ode\%2orevis\%C3\%A3o.pdf.

FERREIRA, Adriane Guedes. QUÍMICA FORENSE E TÉCNICAS UTILIZADAS EM RESOLUÇÕES DE CRIMES. Acta de Ciências e Saúde, Brasília, v. 2, n. 5, p. 32-44, 2016. Disponível em: https://www2.ls.edu.br/actacs/index.php/ACTA/article/view/rzı.

FINDLEY, K.A. DNA Exonerations. Encyclopedia Of Forensic Sciences, [S.L.], p. 454-458, 2013. Elsevier. http://dx.doi.org/10.1016/b978-0-12-382165-2.00223-3. Disponível em: https://www.sciencedirect.com/science/article/pii/B9780123821652002233.

FONNEL $\varnothing \mathrm{P}$, Ane Elida et al. A retrospective study on the transfer, persistence and recovery of sperm and epithelial cells in samples collected in sexual assault casework. Forensic Science International: Genetics, [S.L.], v. 43, p. I02-153, nov. 2019. 
Elsevier BV. http://dx.doi.org/ro.ıor6/j.fsigen.2019.102153. Disponível em: https://www.sciencedirect.com/science/article/abs/pii/Si872497319301346.

FROHLICH, Paula Battistetti Medeiros et al. O DNA COMO FERRAMENTA DE IDENTIFICAÇÃO HUMANA E A SUA RELEVÂNCIA PARA A ATUAÇÃO JURÍDICA. Revista Biodiversidade, [S.L.], v. I9, n. I, p. 150, o2 abr. 2020--. Disponível

em: https://periodicoscientificos.ufmt.br/ojs/index.php/biodiversidade/article/view/ıo oor.

GARALI, Imene et al. Improvements and inter-laboratory implementation and optimization of blood-based single-locus age prediction models using DNA methylation of the ELOVL2 promoter. Scientific Reports, [S.L.], v. Io, n. I, 24 set. 2020. Springer Science and Business Media LLC. http://dx.doi.org/Io.1038/s41598020-72567-6. Disponível em: https://www.nature.com/articles/s41598-020-72567-6.

HAMPIKIAN, Greg; WEST, Emily; AKSELROD, Olga. The Genetics of Innocence: analysis of 194 u.s. dna exonerations. Annual Review Of Genomics And Human Genetics, [S.L.], v. I2, n. I, p. 97-I20, 22 set. 201I. Annual Reviews. http://dx.doi.org/ro.I146/annurev-genom-082509-I41715. Disponível em: https://pubmed.ncbi.nlm.nih.gov/2172194I/.

INNOCENCE PROJECT. DNA exonerations in the United States. Disponível em: https://innocenceproject.org/dna-exonerations-in-the-united-states/

KADER, Farzeen; GHAI, Meenu. DNA methylation and application in forensic sciences. Forensic Science International, [S.L.], v. 249, p. 255-265, abr. 2015. Elsevier BV. http://dx.doi.org/ro.ror6/j.forsciint.2015.01.037. Disponível em: https://www.sciencedirect.com/science/article/abs/pii/S03790738150005Ir?via\%3Di hub.

LEITE, F. et al. DNA Forense: Exames de DNA Humano. Criminalística procedimentos e metodologias. I ed, 242-243, 2005.

MATTE, Melinda et al. Prevalence and persistence of foreign DNA beneath fingernails. Forensic Science International: Genetics, [S.L.], v. 6, n. 2, p. 236-243, mar. 2012. Elsevier BV. http://dx.doi.org/ı.1016/j.fsigen.2011.05.008. Disponível em: https://www.sciencedirect.com/science/article/abs/pii/Si872497311001190.

MCSWIGGAN, Sally; ELGER, Bernice; APPELBAUM, Paul S. The forensic use of behavioral genetics in criminal proceedings: case of the maoa-1 genotype. International Journal of Law And Psychiatry, [S.L.], v. 50, p. 17-23, nov. 2016. Elsevier BV. http://dx.doi.org/ı.1016/j.ijlp.2016.09.005. Disponível em: https://pubmed.ncbi.nlm.nih.gov/27823806/. 
MILLARD, George Henry. ASPECTOS CIENTÍfICOS, TÉCNICOS, ÉTICOS E LEGAIS DO DNA. FORENSE. 2015. $122 \mathrm{f}$. Tese (Doutorado) - Curso de Biotecnologia, Centro de Ciências Exatas e de Tecnologia Programa de PósGraduação em Biotecnologia, Universidade Federal de São Carlos, São Carlos, 2015. Disponível em: https://repositorio.ufscar.br/bitstream/handle/ufscar/78II/TeseGHM.pdf?sequenc $\mathrm{e}=3$ \& is Allowed $=\mathrm{y}$.

MOHER, David; LIBERATI, Alessandro; TETZLAFF, Jennifer; ALTMAN, Douglas G.. Preferred Reporting Items for Systematic Reviews and Meta-Analyses: the prisma statement. Plos Medicine, [S.L.], v. 6, n. 7, p. I000097, 21 jul. 2009. Public Library of Science (PLoS). http://dx.doi.org/Io.1371/journal.pmed.Ioooog7. Disponível em: https://journals.plos.org/plosmedicine/article?id=10.137I/journal.pmed.Ioooo97.

NAUEA, Jana; SÄNGER, Timo; HOEFSLOOT, Huub C.J.; LUTZ-BONENGEL, Sabine; KLOOSTERMAN, Ate D.; VERSCHURE, Pernette J.. Proof of concept study of age-dependent DNA methylation markers across different tissues by massive parallel sequencing. Forensic Science International: Genetics, [S.L.], v. 36, p. 152-159, set. 2018. Elsevier BV. http://dx.doi.org/10.1016/j.fsigen.2018.07.007. Disponível em: https://www.sciencedirect.com/science/article/abs/pii/Si872497318301236.

NURIT, Bublil et al. Evaluating the prevalence of DNA mixtures found in fingernail samples from victims and suspects in homicide cases. Forensic Science International: Genetics, [S.L.], v. 5, n. 5, p. 532-537, nov. 20II. Elsevier BV. http://dx.doi.org/ro.ror6/j.fsigen.2010.12.003. Disponível em: https://www.sciencedirect.com/science/article/abs/pii/Si8724973100or936.

PAES, Rosilda; RIBEIRO, Iraquitan. Importância do DNA Forense para a Biologia Moderna: uma Revisão. Ensaios e Ciência: Ciências Biológicas, Agrárias e da Saúde, Campo Grande, v. 20, p. 30-37, 2016. Disponível em: https://www.redalyc.org/articulo.oa?id=260457780o5.

PAULINO, Renata di Martini; CONCEIÇÃO, Thelma da Silva; DECANINE, Daniele. Análise de laudos periciais correspondentes a vítimas de estupro em Mato Grosso do Sul. Revista Brasileira de Criminalística, [S.L.], v. 6, n. 2, p. 38-42, 8 jul. 2017. Associação Brasileira de Criminalística - ABC. http://dx.doi.org/ro.1526o/rbc.v6i2.174. Disponível em: http://rbc.org.br/ojs/index.php/rbc/article/view/r74.

RAMOS, Phola; HANDTA, Oliva; TAYLOR, Duncan. Investigating the position and level of DNA transfer to undergarments during digital sexual assault. Forensic Science International: Genetics, [S.L.], v. 47, p. 102-316, jul. 2020. Elsevier BV. http://dx.doi.org/ı.1016/j.fsigen.2020.102316. Disponível em: https://www.sciencedirect.com/science/article/abs/pii/Si872497320300892. 
SANTOS, Anderson Eduardo dos. As principais linhas da biologia forense e como auxiliam na resolução de crimes. Revista Brasileira de Criminalística, [S.L.], v. 7, n. 3, p. 12-20, 25 out. 2018. Associacao Brasileira de Criminalistica - ABC. http://dx.doi.org/ro.1526o/rbc.v7i3.19o. Disponível em: http://rbc.org.br/ojs/index.php/rbc/article/view/roo/pdf.

SCHLLER, Werner; SCHEITHAUER, Richard (ed.). INTERPOL HANDBOOK ON DNA DATA EXCHANGE AND PRACTICE: recommendations from the interpol dna monitoring expert group. França: Second Edition, 2009. II8 p.

SOHRABI, S. The criminal gene: the link between maoa and aggression (review). Bmc Proceedings, [S.L.], v. 9, n. jan. 2015. Semestral. Springer Science and Business Media LLC. http://dx.doi.org/Io.II86/1753-656I-9-si-a49. Disponível em: https://www.ncbi.nlm.nih.gov/pmc/articles/PMC4306065/.

WANG, Li-Feng et al. Tri-allelic pattern of short tandem repeats identifies the murderer among identical twins and suggests an embryonic mutational origin. Forensic Science International: Genetics, [S.L.], v. 16, p. 239-245, maio 2015. Elsevier BV. http://dx.doi.org/ı.ıor6/j.fsigen.2015.or.oro. Disponível em: https://www.sciencedirect.com/science/article/abs/pii/S I872497315000289.

WESTRING, Christian G. et al. SPERM HY-LITER ${ }^{\mathrm{TM}}$ for the identification of spermatozoa from sexual assault evidence. Forensic Science International: Genetics, [S.L.], v. I2, p. 16I-167, set. 2014. Elsevier BV. http://dx.doi.org/ro.roi6/j.fsigen.2014.06.003. Disponível em: https://www.sciencedirect.com/science/article/abs/pii/Si872497314001215. 